\title{
The Farnsworth-Munsell 100 hue test in the first episode of demyelinating optic neuritis
}

\author{
M J Ménage, D Papakostopoulos, J C Dean Hart, S Papakostopoulos, Yu Gogolitsyn
}

\begin{abstract}
The Farnsworth-Munsell 100 hue test (F-M 100) was used to examine 30 patients with their first episode of unilateral demyelinating optic neuritis (DON) at presentation, after 6 weeks and after 6 months. Twelve patients satisfactorily completed the test with the affected eye at presentation. This number had increased to 23 by 6 weeks and to 27 by 6 months. No patient with a visual acuity of LogMAR 0.86 (Snellen equivalent approx 6/43) or worse, could complete the test. The mean total error score of affected eyes showed significant improvement at each subsequent examination but was always worse than the non-affected eyes. There was a significant correlation between total error scores and visual acuities of affected eyes at presentation and after 6 months. Fourteen patients recovered a visual acuity of LogMAR 0.0 (Snellen equivalent 6/6) or better but the total error scores of the affected eyes were significantly worse than the non-affected eyes $(p=0.017)$, indicating that defective colour vision is an indicator of a previous episode of DON despite the recovery of normal visual acuity. DON is reported to produce a red-green (Type II) axis of colour defect but individual F-M 100 polar diagrams were usually generally abnormal and did not show any predominance of recognisable axis of colour defect at any examination. Group averaging of the F-M 100 data from such a welldefined group of patients with acute DON revealed a significant bipolar abnormality in the tritan (blue-yellow) axis at presentation which was not demonstrated at the subsequent examinations or at any examination of the nonaffected eyes.

(British f Ophthalmol 1993; 77: 68-74)
\end{abstract}

Bristol Eye Hospital, Lower Maudlin Street, Bristol BS1 2LX

$M \mathrm{~J}$ Ménage

D Papakostopoulos

J C Dean Hart

S Papakostopoulos

Research Centre, 'Brain', St Petersburg, Russia

Y Gogolitsyn

Correspondence to:

Mr M J Ménage.

Accepted for publication

27 October 1992
Demyelinating optic neuritis $(\mathrm{DON})^{12}$ is a relatively common condition, usually affecting young adults, which often causes a profound disturbance of optic nerve function. A marked reduction in colour discrimination is frequently found in the affected eye along with other manifestations of optic nerve dysfunction. In the majority of cases the visual function, including colour vision, gradually improves as the patient recovers. A significant number of patients complain of reduced function in the affected eye when compared with the non-affected eye. Colours look 'washed-out', and this symptom can be enhanced by fatigue or a rise in body temperature. ${ }^{34}$

Acquired defects of colour vision are often categorised by reference to the characteristic defects of congenital colour vision abnormalities. These are deutan, so called green blind, protan, so called red blind, and tritan, so called blue blind. ${ }^{5}$ Acquired defects of colour vision have been further classified by Verriest ${ }^{6}$ into Type 1 (red/green, protan-like with little or no blue/ yellow discrimination abnormality), Type II (red/green, deutan-like with a concomitant mild abnormality of blue/yellow discrimination), and Type III (blue/yellow with a lesser abnormality of red/green discrimination). Optic nerve disease, such as DON, is reported to produce Type II red-green colour defects on colour vision testing, while in contrast, macular disease is reported to produce Type III blue-yellow defects. ${ }^{6-12}$ There are well recognised exceptions ${ }^{610-14}$ to this Köllner rule, ${ }^{7}$ notably glaucoma which commonly produces a Type III tritan defect of colour vision. ${ }^{15}$ It is postulated that Type II red-green defects occur in optic neuropathies such as DON, in which the papillomacular bundle has been disturbed, producing a central field defect with reduced visual acuity, whereas Type III tritan defects occur in optic neuropathies such as glaucoma where there is relative sparing of the central visual function. ${ }^{12}$

It might be supposed that, in subtle cases of DON where the diagnosis may be in doubt, the finding of a red-green defect would be of some diagnostic value. However, it has proved impossible to use the different colour defects to distinguish partially resolved DON from a disturbance of the macula such as central serous retinopathy. ${ }^{16}$

The Farnsworth-Munsell 100 hue test (F-M $100)$ is one of the most widely used clinical tests of acquired defects of colour vision. It was originally conceived as a test of congenital colour abnormality, ${ }^{517}$ but has come to be used for categorising and quantifying acquired defects. ${ }^{6118}$ It is reported to be one of the most useful clinical tests of acquired colour vision defect in optic nerve disease, ${ }^{119}$ and more particularly optic neuritis. ${ }^{20}$ Optic neuritis patients have a generalised loss of colour function but are able to make at least minimal discriminations in all directions in colour space, hence the failure of most tests using pseudo-isochromatic plates, which rely on absolute defects, to demonstrate the disturbance of colour vision. ${ }^{21}$ The F-M 100 
Table 1 Criteria for entry of patients to the study

1 Age 18 to 50 years.

No previous episode of optic neuritis or previous diagnosis of multiple sclerosis.

No history of congenital colour vision abnormality.

Normal vision in both eyes before the acute optic neuritis.

Reduced acuity in the affected eye at presentation to the casualty department.

Relative afferent pupillary defect in the affected eye at presentation to the casualty department.

presentation to the casualty department.
Significant delay in the visual evoked potential in the affected eye ( $\geq 3$ SD of the mean of a normal population).

8 First examination within 31 days of the onset of any symtoms.

samples the colour diagram in all directions and indicates the degree and orientation of discrimination throughout the colour field.

The purpose of our study was to evaluate the use of the F-M 100 in patients with DON, and to qualify the defect of colour vision in the acute and recovery phases of the disease.

\section{Patients and methods}

Thirty patients presenting with a first episode of acute unilateral DON to the casualty department of the Bristol Eye Hospital were studied over a 30 month period. There were extensive criteria for referral for the study (Table 1), to select as welldefined a population as possible.

Three of the patients also had a significant delay in the visual evoked potential (VEP) in the non-affected eye $(\geq 3 \mathrm{SD}$ of the mean of a normal population), although there was no correspond- ing significant abnormality of visual acuity or colour vision in this eye.

The average age of the accepted patients was 33 years (range 20-47) and 20 were female and 10 male. The left eye was affected in 18 and the right in 12. Average time of initial test after onset of any symptoms was 15 days (range 4-29).

Visual acuity was measured using the chart described by Ferris $e t a l^{22}$ used in the Early Treatment Diabetic Retinopathy Study, which has a geometric progression in letter size from line to line, and equal numbers of letters of equal difficulty on each line. Best corrected visual acuity was expressed using a logarithmic (Log MAR) scale. Patients were tested with any required spectacle correction and with a pinhole in the usual manner. The non-affected eye was always tested first.

Visual acuity measurement and F-M 100 were carried out at presentation and repeated 6 weeks after onset of symptoms and again after 6 months. Six weeks provided an appropriate interval for a definite improvement in colour vision to appear and after 6 months significant further improvement was unlikely.

The F-M 100 has been extensively described. 511171920 The 85 coloured caps in four cases were presented under CIE Illuminant ' $C$ ' illumination using the Macbeth Easel Lamp ADE 10, as recommended by Farnsworth. ${ }^{5}$ The non-affected eye was tested first and the cases were presented in numerical order. The patients

Table 2 LogMAR visual acuity and F-M 100 total error scores of all patients at all three examinations

\begin{tabular}{|c|c|c|c|c|c|c|c|c|c|c|c|c|c|}
\hline \multirow{3}{*}{$\begin{array}{l}\text { Patient } \\
\text { no }\end{array}$} & \multirow{3}{*}{$\begin{array}{l}\text { Age } \\
\text { (years) }\end{array}$} & \multicolumn{4}{|c|}{ Examination 1} & \multicolumn{4}{|c|}{ Examination 2} & \multicolumn{4}{|c|}{ Examination 3} \\
\hline & & \multicolumn{2}{|c|}{ Affected } & \multicolumn{2}{|c|}{ Non-affected } & \multicolumn{2}{|c|}{ Affected } & \multicolumn{2}{|c|}{ Non-affected } & \multicolumn{2}{|c|}{ Affected } & \multicolumn{2}{|c|}{ Non-affected } \\
\hline & & $\overline{V A}$ & $T E S$ & $V A$ & TES & $V A$ & $T E S$ & $V A$ & $T E S$ & $V A$ & TES & $V A$ & TES \\
\hline $\begin{array}{r}1 \\
2 \\
3 \\
4 \\
5 \\
6 \\
7 \\
8 \\
9 \\
10 \\
11 \\
12 \\
13 \\
14 \\
15 \\
16 \\
17 \\
18 \\
19 \\
20 \\
21 \\
22 \\
23 \\
24 \\
25 \\
26 \\
27 \\
28 \\
29 \\
30\end{array}$ & $\begin{array}{l}42 \\
39 \\
31 \\
28 \\
38 \\
41 \\
27 \\
34 \\
20 \\
35 \\
22 \\
34 \\
31 \\
45 \\
36 \\
41 \\
42 \\
35 \\
28 \\
22 \\
43 \\
22 \\
44 \\
41 \\
21 \\
25 \\
27 \\
47 \\
20 \\
34\end{array}$ & $\begin{array}{c}-0.02 \\
1.60 \\
0.50 \\
0.00 \\
0.20 \\
0.18 \\
0.02 \\
1.06 \\
0.24 \\
\mathrm{PL} \\
\mathrm{HM} \\
-0.10 \\
0.16 \\
\mathrm{HM} \\
1.64 \\
0.06 \\
0.82 \\
1.62 \\
1.00 \\
0.52 \\
0.86 \\
\mathrm{CF} \\
\mathrm{CF} \\
0.22 \\
0.12 \\
0.06 \\
1.36 \\
0.14 \\
0.40 \\
\mathrm{CF}\end{array}$ & $\begin{array}{l}24 \\
\text { NM } \\
660^{\star} \\
112 \\
308 \\
520^{\star} \\
212 \\
\text { NM } \\
228 \\
\text { NM } \\
\text { NM } \\
96 \\
292 \\
N M \\
N M \\
220 \\
480^{\star} \\
\text { NM } \\
\text { NM } \\
408 \\
\text { NM } \\
\text { NM } \\
\text { NM } \\
120 \\
188 \\
124 \\
\text { NM } \\
\text { NM } \\
\text { NM } \\
\text { NM }\end{array}$ & $\begin{array}{r}-0.08 \\
-0.10 \\
-0.10 \\
-0.06 \\
-0.10 \\
0.00 \\
-0.08 \\
-0.22 \\
-0.10 \\
-0.16 \\
-0.04 \\
-0.20 \\
-0.16 \\
-0.10 \\
-0.06 \\
-0.04 \\
-0.06 \\
0.04 \\
0.02 \\
0.06 \\
-0.04 \\
-0.02 \\
-0.08 \\
-0.20 \\
-0.18 \\
-0.14 \\
-0.10 \\
0.00 \\
0.10 \\
0.00\end{array}$ & $\begin{array}{r}20 \\
140 \\
116 \\
60 \\
92 \\
168 \\
56 \\
104 \\
104 \\
56 \\
44 \\
44 \\
64 \\
80 \\
200 \\
64 \\
48 \\
48 \\
60 \\
60 \\
96 \\
64 \\
124 \\
24 \\
100 \\
8 \\
172 \\
52 \\
76 \\
152\end{array}$ & $\begin{array}{r}-0.10 \\
-0.10 \\
-0.10 \\
-0.08 \\
-0.02 \\
0.02 \\
0.04 \\
0.18 \\
-0.10 \\
1.60 \\
0.74 \\
-0.04 \\
-0.06 \\
1.60 \\
0.04 \\
-0.02 \\
0.12 \\
0.00 \\
-0.04 \\
0.10 \\
0.66 \\
1.00 \\
0.18 \\
0.08 \\
0.12 \\
-0.02 \\
0.24 \\
0.08 \\
0.22 \\
0.34\end{array}$ & $\begin{array}{c}40 \\
188 \\
152 \\
24 \\
72 \\
200 \\
84 \\
456^{\star} \\
148 \\
\text { NM } \\
580^{\star} \\
68 \\
168 \\
\text { NM } \\
264 \\
188 \\
308 \\
64 \\
40 \\
80 \\
428 \\
\text { NM } \\
312 \\
140 \\
152 \\
56 \\
\text { NM } \\
252 \\
20 \\
\text { NM }\end{array}$ & $\begin{array}{r}-0.10 \\
-0.10 \\
-0.10 \\
-0.08 \\
-0.02 \\
0.04 \\
-0.06 \\
-0.20 \\
-0.16 \\
-0.06 \\
0.00 \\
-0.20 \\
-0.16 \\
-0.10 \\
-0.06 \\
-0.06 \\
-0.10 \\
0.00 \\
-0.06 \\
0.10 \\
-0.02 \\
-0.18 \\
-0.08 \\
-0.20 \\
-0.18 \\
-0.20 \\
-0.12 \\
-0.08 \\
0.04 \\
0.12\end{array}$ & $\begin{array}{r}20 \\
132 \\
116 \\
36 \\
56 \\
76 \\
68 \\
128 \\
56 \\
40 \\
32 \\
32 \\
96 \\
60 \\
192 \\
52 \\
40 \\
48 \\
40 \\
64 \\
76 \\
60 \\
120 \\
84 \\
144 \\
4 \\
196 \\
16 \\
48 \\
176\end{array}$ & $\begin{array}{r}-0.04 \\
-0.12 \\
-0.18 \\
0.00 \\
-0.04 \\
0.04 \\
0.00 \\
0.42 \\
-0.08 \\
0.84 \\
0.16 \\
-0.18 \\
0.10 \\
0.40 \\
0.00 \\
-0.08 \\
0.08 \\
0.00 \\
-0.10 \\
0.02 \\
0.32 \\
0.06 \\
0.02 \\
0.00 \\
0.20 \\
0.06 \\
0.06 \\
0.04 \\
-0.06 \\
0.40\end{array}$ & $\begin{array}{r}20 \\
104 \\
120 \\
16 \\
68 \\
228 \\
48 \\
\text { NM } \\
104 \\
\text { NM } \\
388 \\
36 \\
180 \\
268 \\
340 \\
140 \\
404 \\
72 \\
44 \\
108 \\
280 \\
120 \\
144 \\
104 \\
100 \\
16 \\
312 \\
184 \\
20 \\
632^{\star}\end{array}$ & $\begin{array}{r}-0.04 \\
-0.08 \\
-0 \cdot 18 \\
0.00 \\
-0.02 \\
-0.02 \\
0.00 \\
0.14 \\
-0.18 \\
-0.08 \\
0.04 \\
-0.16 \\
-0.16 \\
0.00 \\
-0.06 \\
-0.04 \\
-0.08 \\
0.02 \\
-0.06 \\
0.00 \\
0.06 \\
-0.10 \\
0.00 \\
-0 \cdot 12 \\
-0.10 \\
-0.06 \\
-0.18 \\
0.02 \\
0.04 \\
0.14\end{array}$ & $\begin{array}{r}16 \\
128 \\
72 \\
16 \\
28 \\
88 \\
80 \\
252 \\
68 \\
16 \\
44 \\
24 \\
92 \\
44 \\
204 \\
36 \\
52 \\
32 \\
40 \\
24 \\
72 \\
24 \\
20 \\
56 \\
144 \\
0 \\
148 \\
100 \\
40 \\
236\end{array}$ \\
\hline
\end{tabular}

$\mathrm{VA}=$ visual acuity; $\mathrm{TES}=$ total error scores; $\mathrm{NM}=$ non-measurable; $\mathrm{CF}=$ count fingers; $\mathrm{HM}=$ hand movements; $\mathrm{PL}=$ perception of light; $\star=$ excluded score.

Table 3 Changes in total error score for Group $A(n=12)$

\begin{tabular}{|c|c|c|c|c|c|c|c|c|}
\hline & \multicolumn{2}{|c|}{ Examination 1 (presentation) } & \multirow[b]{2}{*}{ p Value } & \multicolumn{2}{|c|}{ Examination 2 (6 weeks) } & \multirow[b]{2}{*}{ p Value } & \multicolumn{2}{|c|}{ Examination 3 (6 months) } \\
\hline & $\operatorname{Mean}(S D)$ & Median & & $\operatorname{Mean}(S D)$ & Median & & $\operatorname{Mean}(S D)$ & Median \\
\hline $\begin{array}{l}\text { Affected eyes } \\
\text { Non-affected eyes } \\
\text { p Value }\end{array}$ & $\begin{array}{c}194(107) \\
58(31) \\
0.003\end{array}$ & $\begin{array}{r}200 \\
60\end{array}$ & $\begin{array}{l}0.005 \\
\text { NS }\end{array}$ & $\begin{array}{r}102(55) \\
59(37) \\
0.004\end{array}$ & $\begin{array}{l}82 \\
56\end{array}$ & $\begin{array}{l}0.017 \\
0.031\end{array}$ & $\begin{array}{r}78(52) \\
49(41) \\
0.019\end{array}$ & $\begin{array}{l}84 \\
32\end{array}$ \\
\hline
\end{tabular}


Table 4 Changes in total error score for Group $B(n=23)$

\begin{tabular}{|c|c|c|c|c|c|}
\hline & \multicolumn{2}{|c|}{ Examination 2 (6 weeks) } & \multirow[b]{2}{*}{$p$ Value } & \multicolumn{2}{|c|}{ Examination 3 ( 6 months) } \\
\hline & Mean $(S D)$ & Median & & Mean $(S D)$ & Median \\
\hline $\begin{array}{l}\text { Affected eyes } \\
\text { Non-affected eyes } \\
\text { p Value }\end{array}$ & $\begin{array}{l}150(107) \\
70(46) \\
<0.001\end{array}$ & $\begin{array}{r}148 \\
56\end{array}$ & $\begin{array}{l}0.041 \\
\text { NS }\end{array}$ & $\begin{array}{c}125(105) \\
62(48) \\
0.001\end{array}$ & $\begin{array}{r}104 \\
52\end{array}$ \\
\hline
\end{tabular}

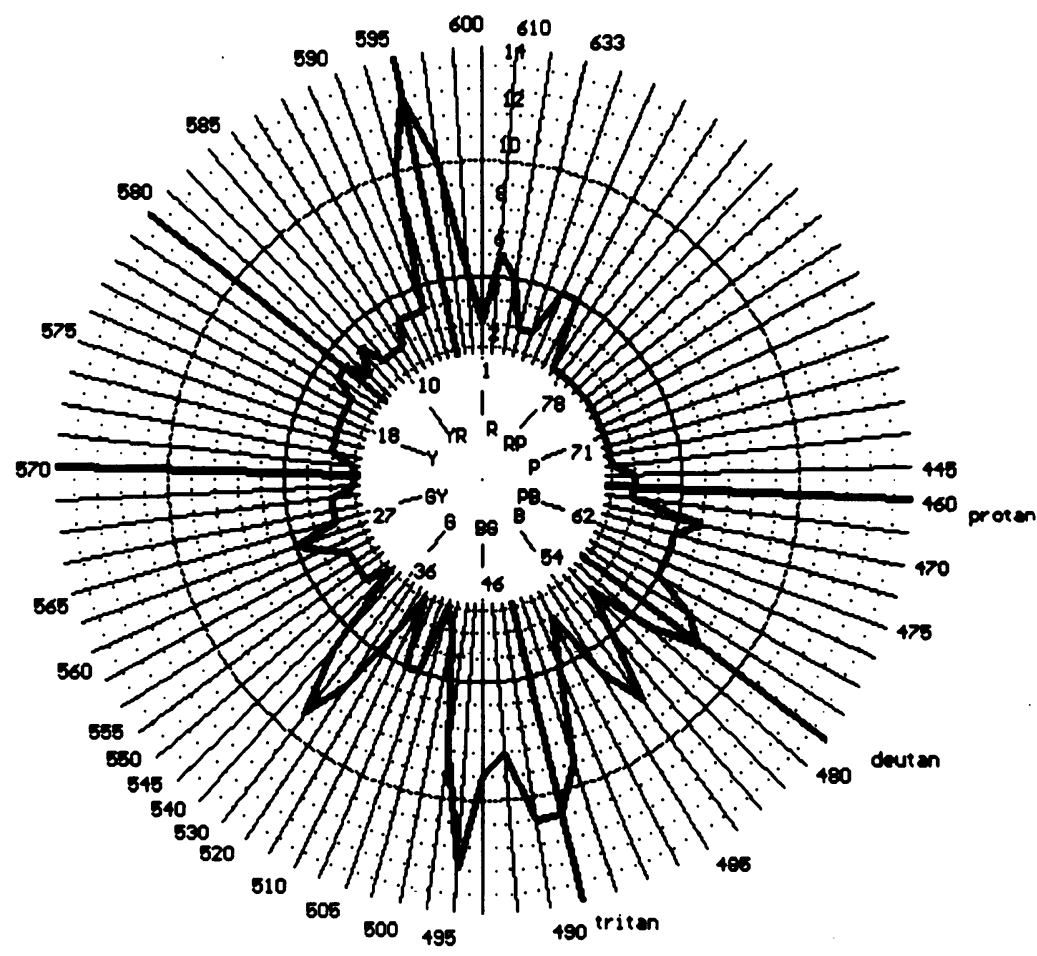

Figure 1 Example of a $F-M 100$ polar diagram for the affected eye of a patient at presentation.
Table 5 Total error scores Group $C(n=27)$

\begin{tabular}{llc}
\hline & \multicolumn{2}{c}{ Examination 3(6 months) } \\
\cline { 2 - 3 } & Mean $(S D)$ & Median \\
\hline Affected eyes & $147(116)$ & 108 \\
Non-affected eyes & $61(46)$ & 44 \\
p Value & $<0.001$ & \\
\hline
\end{tabular}

complete the test at every examination with the non-affected eye.

Age-matched limits of normality of total error score for the F-M 100 have been defined by Krill and Fishman ${ }^{11}$ as a modification of Verriest's earlier work. ${ }^{6}$ A total error score of more than 100 was considered abnormal for those subjects 15 to 29 years old; more than 120 for those 30 to 39 years old; and more than 140 for those 40 to 49 years old.

\section{STATISTICAL ANALYSIS}

The Wilcoxon signed rank test was used to compare total error scores for the separate examinations and visual acuity and total error scores between affected and non-affected eyes. Visual acuity and total error scores were compared using the Spearman rank correlation.

Separate data matrices were constructed for the affected and non-affected eye at all three examinations. The rows of a given data matrix were formed by the individual sets of 85 error scores in the F-M 100, its columns containing errors scored by all the subjects in discriminating the same colour cap with the same eye at a given examination. Because the distribution of error scores is not normal, especially at low scores, non-parametric Wilcoxon signed rank and Mann Whitney $\mathrm{U}$ tests were applied as appropriate. To compare the colour discrimination of the affected versus non-affected eye or of the same eye in the course of the disease, the pairwise comparisons of column data in the two corresponding matrices were used to produce a graph of normalised $\mathrm{z}$-scores versus colour cap number. To determine whether certain colours are discriminated better or worse than others, the column data for all pairs of columns within the same matrix were compared. The resulting $85 \times 85$ square symmetrical matrix also contains normalised $z$-scores and is graphically represented in two dimensions as a binary matrix with units corresponding to $\mathrm{z}$-scores exceeding the specified threshold of significance. patients able to satisfactorily complete the test had increased to 23 and by 6 months had further increased to 27.

For clarification of our data presentation we designated Group A to consist of the 12 patients able to complete the test satisfactorily at all three examinations, Group B to consist of the 23 patients able to satisfactorily complete the test at 6 weeks and 6 months, and Group $C$ to consist of the 27 patients able to satisfactorily complete the test only at 6 months. Obviously subsequent groups cumulatively contain the patients from previous groups.

One patient had suffered a further attack of DON in the same eye and was unable to attempt the test at 6 months. Only one patient was unable to attempt the F-M 100 with the affected eye at all three examinations. All 30 were able to

\section{Results}

Table 2 details the individual F-M 100 total error scores (TES) and LogMAR visual acuities of the patients at all three examinations.

Patients with a visual acuity of $\log$ MAR $0 \cdot 86$

Table 6 Patterns of defect in individual F-M 100 tests of the affected eye

\begin{tabular}{lccc}
\hline & Presentation & 6 Weeks & 6 Months \\
\hline Red-green & 0 & 2 & 3 \\
Blue-yellow & 2 & 0 & 0 \\
Non-specific pattern & 11 & 15 & 13 \\
Normal pattern & 2 & 8 & 12 \\
Not able & 15 & 5 & 2 \\
Total & 30 & 30 & 30 \\
\hline
\end{tabular}




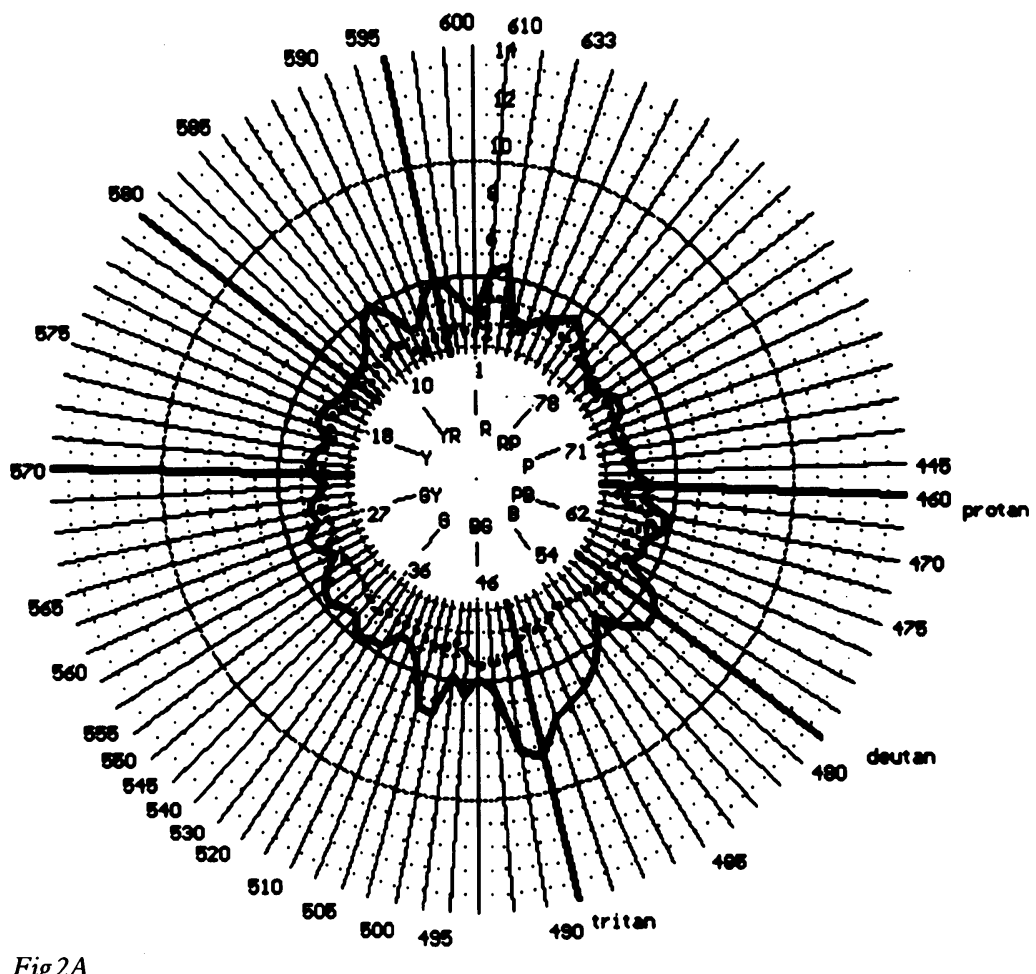

Fig $2 A$

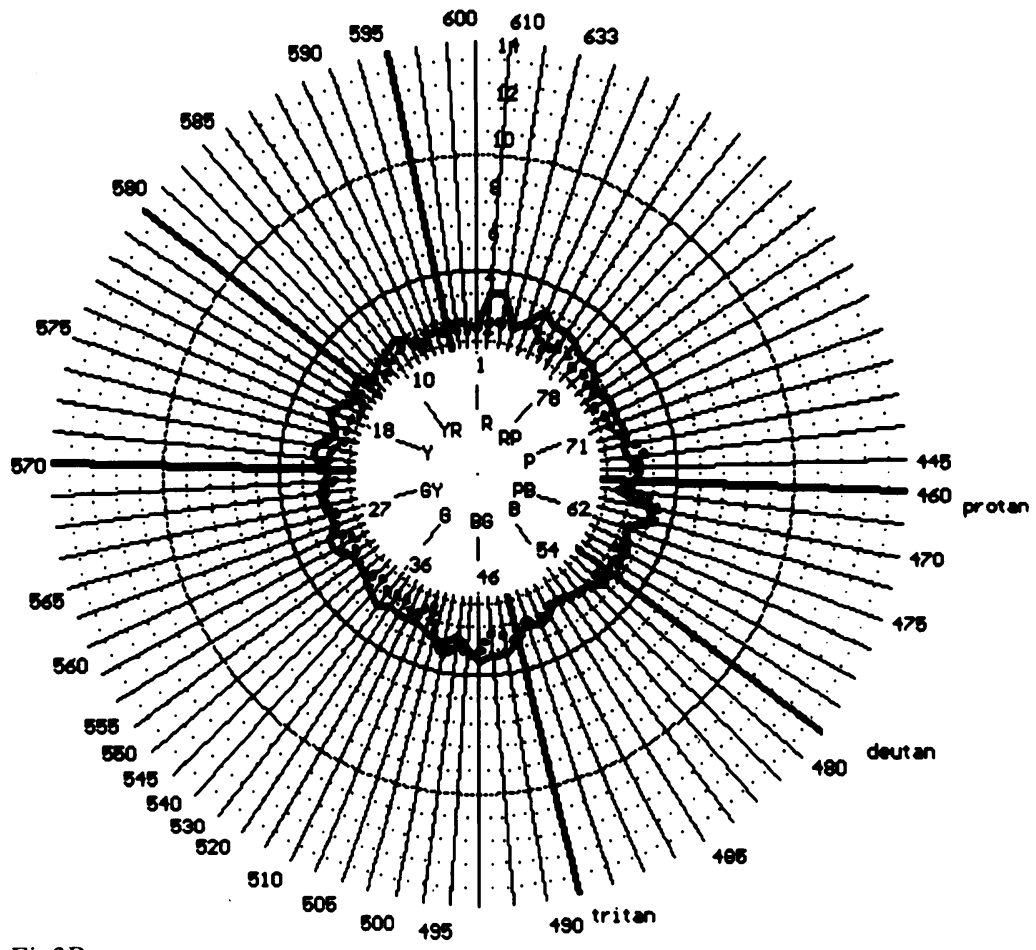

Fig 2B

Figure 2 Composite polar diagrams of the average errors scored by the affected eyes of Group $A(n=12)$. (A) Solid line $=$ examination at presentation and dotted line $=$ examination at 6 weeks. (B) Solid line $=$ examination at 6 weeks and dotted line $=$ examination at 6 months.
(Snellen equivalent approx 6/43) or worse, were unable to attempt the test as they could not see the coloured caps or could not discern any difference between them. Persistence with the test in the affected eye of these individuals was frustrating for the patient and produced total error scores no better than a random arrangement of the caps and certainly no meaningful pattern on the F-M 100 polar diagram.

Table 3 summarises the change in total error scores among the three examinations for Group A $(n=12)$. The affected eyes show significant improvement in total error score with each subsequent examination and are significantly worse than the non-affected eyes at every examination. The non-affected eyes show significant improvement from the 6 week to the 6 month examination.

Table 4 summarises the change in the total error scores between the 6 week and 6 month examination for Group B $(n=23)$. Again, the affected eyes show significant improvement in total error score and are always significantly better than the non-affected eyes.

Table 5 shows the persistently significant total error scores of the affected eyes when compared to the non-affected eyes at 6 months for Group C $(\mathrm{n}=27)$.

Twenty nine patients $(97 \%)$ showed improvement of colour vision in the affected eye with time, with one patient unmeasurable with the F-M 100 at any examination. The most significant improvement had occurred by the 6 week examination with some further improvement at 6 months (Tables 3 and 4).

At the initial examination 27 of the 30 patients $(90 \%)$ had an abnormality of colour vision in the affected eye as demonstrated on the F-M 100 or the abnormality was so great as to render them unable even to attempt the test. By 6 weeks, 19 $(63 \%)$ had a persistent abnormality of colour vision in the affected eye and after 6 months 16 patients $(53 \%)$ had what was likely to be a permanent disturbance of their colour vision.

Fourteen patients recovered normal colour vision in the affected eye by the age-matched limits of normality as defined by Krill and Fishman ${ }^{11}$ and the total error scores of these 14 affected eyes were not significantly worse than the non-affected eyes. Of 14 patients recovering a visual acuity of LogMAR 0.0 (Snellen equivalent $6 / 6$ ) or better only two had definitely abnormal colour vision in the affected eye by the age-matched limits of normality of total error score, although in contrast to the visual acuities, the total error scores of the affected eyes were significantly worse than the non-affected eyes $(\mathrm{p}=0.017)$.

The Spearman rank correlation between visual acuity and total error score in affected eyes was $0.767(p=0.004, n=12)$ at presentation, $0.357(\mathrm{p}=0.095, \mathrm{n}=23)$ at 6 weeks and 0.531 $(\mathrm{p}=0.004, \mathrm{n}=27)$ after 6 months. There were no significant correlations from the non-affected eyes.

Conventional polar diagrams (Fig 1) were produced from the F-M 100 test of each patient at each examination. The diagrams were inspected for recognisable axes of colour defect using Farnsworth's original criteria. ${ }^{5}$ Results are summarised in Table 6. Very few patients demonstrated any recognisable pattern of colour defect at any of the three examinations. Two blue-yellow defects were found at presentation but were not seen thereafter. Two red-green defects were seen at 6 weeks and three after 6 months but the later defects were in different patients.

Individual error scores for each coloured cap of the test were then group-averaged to produce a pair of polar diagrams at each examination for affected and non-affected eyes. Three pairs of such diagrams for the affected eyes of Group A are summarised in Figures $2 \mathrm{~A}$ and $2 \mathrm{~B}$ and for the non-affected eyes in Figures $3 \mathrm{~A}$ and $3 \mathrm{~B}$. 


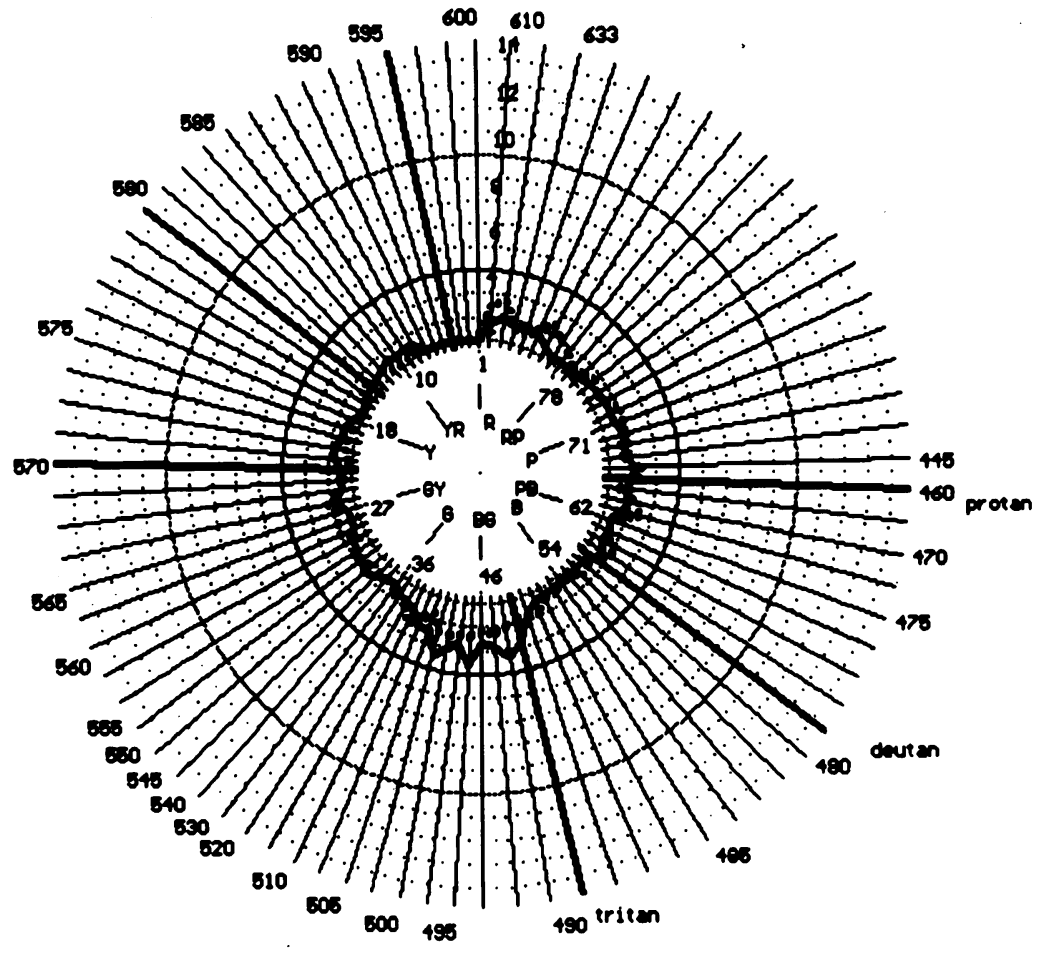

Fig $3 A$

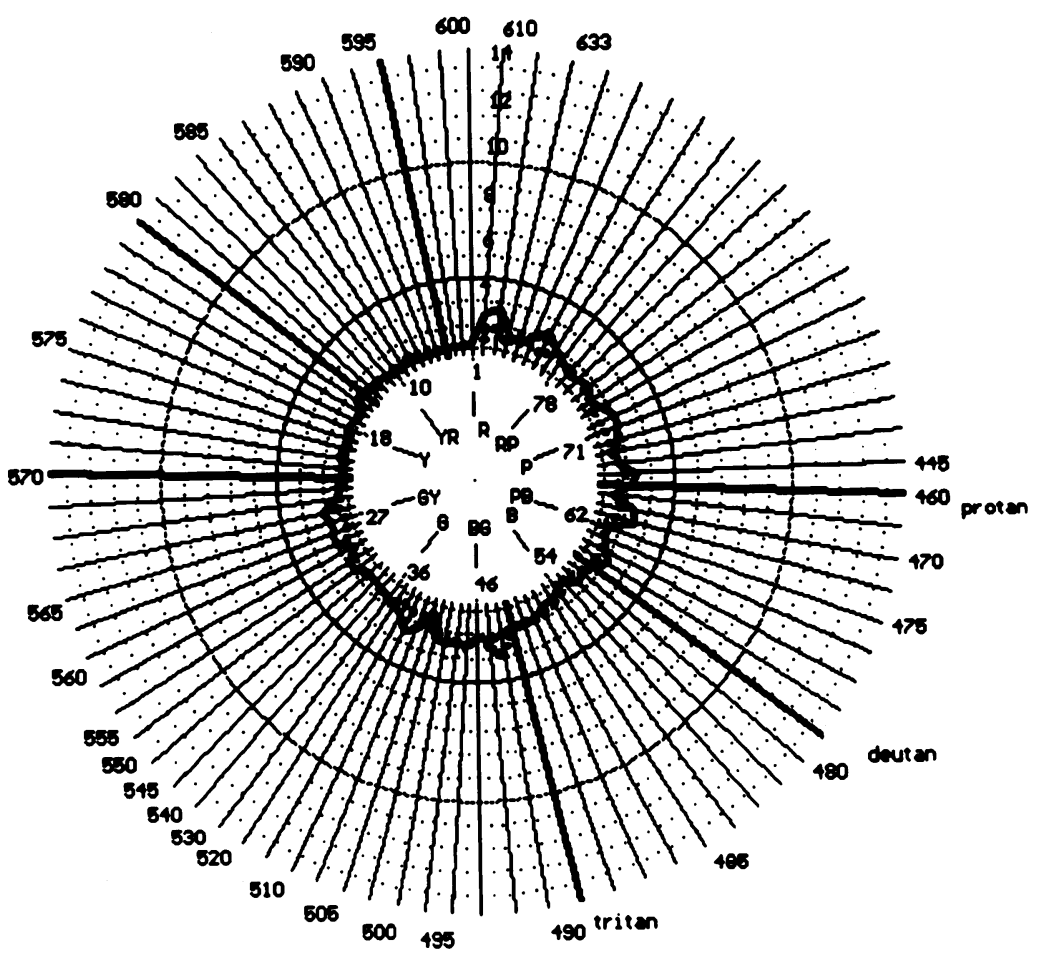

Fig $3 B$

Figure 3 Composite polar diagram of the average errors scored by the non-affected eyes of Group $A(n=12)$. (A) Solid line = examination at presentation and dotted line $=$ examination at 6 weeks. (B) Solid line $=$ examination at 6 weeks and dotted line $=$ examination at 6 months.

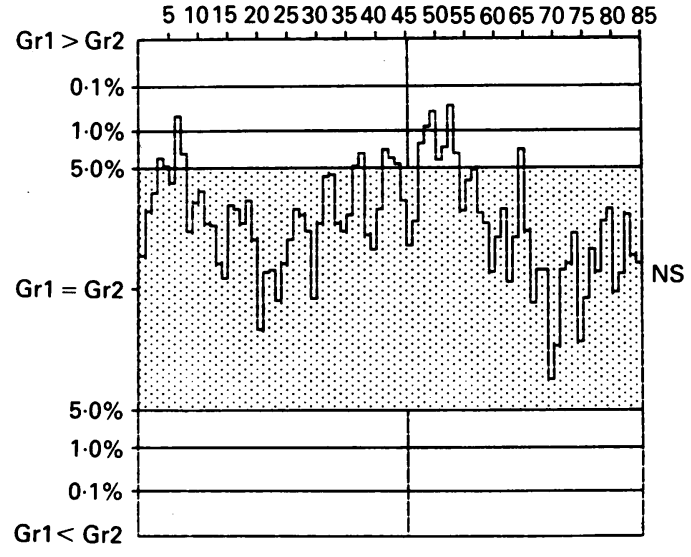

Figure 4 A graph of normalised z-scores (Wilcoxon signed rank test) versus colour cap number for the affected eyes of Group A from examination at presentation to 6 weeks with $p=0.05, p=0.01$, and $p=0.001$ confidence intervals.

Farnsworth's manual for the F-M $100^{5}$ gives a bipolar axis of greatest abnormality passing through coloured caps numbers 46 to 52 for a tritan defect, 56 to 61 for a deutan defect and 62 to 70 for a protan defect. Figures $5 \mathrm{~A}$ and $5 \mathrm{~B}$ show the analysis of the initial examination of the affected and non-affected eyes of Group A for a significant abnormality of the averaged scores of each coloured cap of the F-M 100. This is
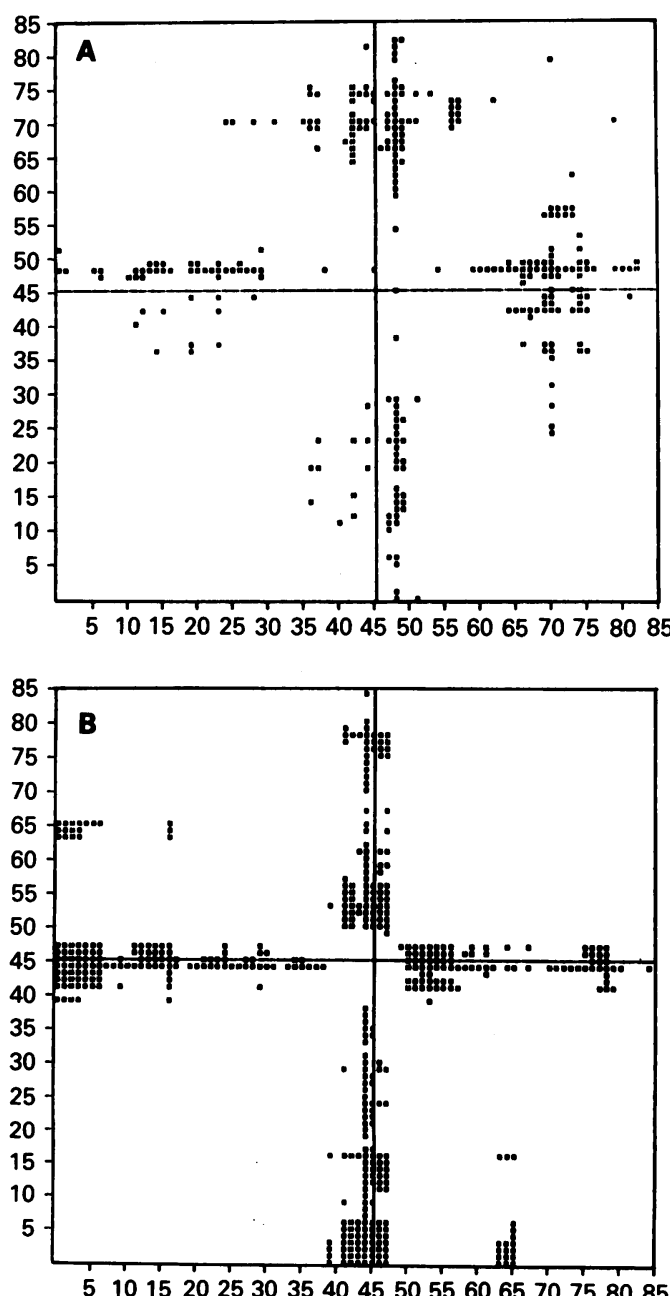

510152025303540455055606570758085 Figure 5 A two-dimensional representation of the $85 \times 85$ square symmetrical matrices of normalised $z$-scores (Wilcoxon signed rank test) resulting from testing all the pairs of colour cap error scores for $n=12$ subjects at the first examination. $Z$-scores exceeding $2 \cdot 80$ threshold $(p=0 \cdot 005)$ are plotted as units. (A) Affected eyes. (B) Non-affected eyes. 
demonstrated in the region of cap 48 in the affected eyes which is consistent with a tritan pattern of colour defect. This abnormality was not demonstrated at any subsequent examinations. The non-affected eyes show a significant defect centred around cap 44, which was consistently demonstrated at all subsequent examinations of both the non-affected and affected eyes.

\section{Discussion}

A predominance of red-green colour defects in DON has been reported by several investigators using combinations of the F-M $100,{ }^{623-26}$ the Farnsworth Panel D-15, ${ }^{624-26}$ the Ishihara pseudoisochromatic plates, ${ }^{62326}$ the HardyRand-Ritter pseudoisochromatic plates, ${ }^{62326}$ the Bostrom Kugelberg pseudoisochromatic plates, ${ }^{24}$ the Standard pseudoisochromatic plates part $2,{ }^{27}$ the Nagel anomaloscope, ${ }^{6}$ the Tokyo Medical College Colour Vision Test, ${ }^{26}$ Lanthony's New Colour Test, Panel D15, ${ }^{27}$ and the City University Colour Vision Test. ${ }^{27}$

Using the F-M 100 we did not find any significant evidence of a red-green colour defect at any of the examinations, either in individual polar diagrams or after group averaging of our data. Apart from the bipolar abnormality in the tritan axis of the affected eyes at presentation that had resolved by 6 weeks, no other specific axis of defect of colour vision was found at the 6 week or 6 month examinations. The majority of studies carried out in the recovered phase of DON or quiescent MS, have found non-specific defects using a wide variety of tests of colour vision. ${ }^{4202528-30}$ By systematic recruitment of cases with onset of symptoms less than 29 days before examination, all the patients in our study were tested early in the acute phase of their first episode of DON. By group averaging of such a well-defined population we were able to reveal a predominant tritan axis of colour defect. One other study that reported a predominance of tritan defects in DON does not detail how early in the disease the paticnts were examined nor whether it was the first episode of DON."

We chose to exclude tests with total error scores over 450 because such grossly abnormal results would artificially distort the data when analysed. This meant the exclusion of only six test results out of the 90 possible examinations of the affected eyes and all the six results showed a generalised gross abnormality of the F-M 100. Other investigators have used similar criteria, ${ }^{19}$ and have also recognised a relationship between a discernible pattern of colour vision defect and a lesser degree of overall disturbance of the visual function. ${ }^{27}$

A consistent finding in analysis of the data for all examinations except that of the affected eyes at presentation was a small but significant abnormality of colour discrimination centred approximately at cap 44 . This has previously been described in normals tested with the F-M $100^{6}$ and probably represents the section of coloured caps that are most difficult to distinguish from each other even by those with apparently normal colour vision. At presentation the affected eyes had such a profound general- ised disturbance of colour vision that this subtle difficulty would have been swamped.

Colour vision is advocated as a sensitive test for DON and is reported to be the first visual function involved and the last to be restored. ${ }^{31}$ Twenty seven $(90 \%)$ of the patients we studied had abnormal colour vision when first seen. Although all 30 had a reduction in visual acuity this was judged in relation to the normal eye whereas colour vision was determined to be abnormal by age-related norms for total error score. We found a very significant correlation between the visual acuity and total error scores for the affected eyes at presentation and at 6 months. At 6 weeks the correlation had a $p$ value of 0.095 . There were no significant correlations from the non-affected eyes. As no patient with a visual acuity of LogMAR 0.86 (Snellen equivalent approx 6/43) or worse, could meaningfully attempt the F-M 100 we would advise against a potentially frustrating and time wasting test in such patients.

Colour vision tests have been used to provide evidence of a previous episode of demyelination of the optic nerve in patients with apparently recovered DON, or quiescent multiple sclero$\operatorname{sis}^{202528-303233}$ and persistent subtle defects of colour vision are cited, along with abnormalities of contrast sensitivity and field defects, as the usual cause of patients continued complaints of poor vision in an eye with a normal visual acuity. ${ }^{2032-35}$ Sixteen (53\%) of the patients studied had a permanent residual abnormality of colour vision. Of 14 patients recovering a visual acuity of LogMAR $0 \cdot 0$ (Snellen equivalent 6/6) or better only two had definitely abnormal colour vision in the affected eye by the age-matched limits of normality of total error score. In contrast to the visual acuities however, the total error scores of the affected eyes of these 14 patients were significantly worse than the non-affected eyes $(p=0.017)$, indicating that defective colour vision is an indicator of a previous episode of DON despite the recovery of normal visual acuity.

There was some slight improvement in the non-affected eye over the three examinations although this only reaches statistical significance for Group A from the 6 week to the 6 month examination (Table 3). This could represent recovery of a subtle lesion of the asymptomatic eye as has been suggested by magnetic resonance imaging and VEP measurement in patients with DON. ${ }^{36}$ Indeed three of our patients had a significant delay in the VEP of the non-affected eye. A more likely explanation is that there is probably an improvement in total error score of the F-M 100 with repeated testing in normals, ${ }^{56}$ although this has been denied by at least one author. ${ }^{19}$

From a clinical point of view there is no doubt that the F-M 100 with its numerical score of colour discrimination provided confirmation and valuable reassurance to both patient and doctor that vision was improving. A compressive lesion of the optic nerve probably represents the most important differential diagnosis and a progressive recovery of visual function would be unlikely in such a situation.

A search for a recognisable axis of defect using 
the F-M 100 in an individual suffering from DON does not offer any diagnostic value but analysis of our data has demonstrated a significant Type III tritan axis of colour defect early in the acute phase of the disease.

The authors are grateful to Mrs Gill Bennerson for photographic help.

This work was supported by a grant from the District Medical Committee, United Bristol Hospitals.

1 Bradley WG, Whitty CWM. Acute optic neuritis: its clinical features and their relation to prognosis for recovery of vision. f Neurol Neurosurg Psychiatry 1967; 30: 531-8.

2 McDonald WI. Acute optic neuritis. Br f Hosp Med 1977 42-8.

3 Uhthoff $W$. Untersuchungen uber die bei der multiplen Herdsklerose verkommenden Augenstorungen. Arch Psychiat Nervenkr 1890; 21: 303, 420.

4 Steinmetz RD, Kearns TP. H-R-R pseudo-isochromatic plates as a diagnostic aid in retrobulbar neuritis of multiple pclerosis. Am $\mathcal{f}$ Ophthalmol 1956; 41: 833-7.

5 Farnsworth D. The Farnsworth-Munsell 100 Hue test for the examination of colour discrimination. In: Manual. examination of colour discrimination.
Baltimore, $M D$ : Munsell Colour, 1957: 2-17.

6 Verriest G. Further studies on acquired deficiency of colour discrimination. F Opt Soc Am 1963; 53: 185-95.

7 Köllner H. Die Störungen des Farbensinnes, ihre klinische Bedeutung und ihre Diagnose. Berlin: Karger, 1912.

8 Mullen KT, Plant GT. Colour and luminance vision in human optic neuritis. Brain 1986; 109: 1-13.

9 Compston A. Cellular organisation of the optic nerve and the implications for optic neuritis. Eye 1992; 6: 123-8.

10 Verriest G. On acquired deficiency of colour vision. Vis Res $1961 ; 1: 201-19$.

11 Krill AE, Fishman GA. Acquired colour vision defects. Trans Am Acad Ophthalmol Otol 1971; 75: 1095-111.

12 Hart WM. Acquired dyschromatopsias. Surv Ophthalmol 1987; 32: 10-31

13 Hong S-M. Types of acquired colour vision defects. Arch Ophthalmol 1957; 58: 505-9.

14 Jaeger $W$. Defective colour-vision caused by eye diseases. Trans Ophthalmol Soc UK 1956; 76: 477-89.

15 Sample PA, Weinreb RN, Boynton RN. Acquired dyschromatopsias in glaucoma. Surv Ophthalmol 1986; 31: 54-64.

16 Han DP, Thompson HS, Folk JC. Differentiation between recently resolved optic neuritis and central serous retinopathy. Arch Ophthalmol 1985; 103: 394-6.

17 Farnsworth D. The Farnsworth-Munsell 100 Hue and dichotomous tests for colour vision. 7 Opt Soc Am 1943; 33: 568-78.

18 Ohta Y. Studies on acquired anomalous colour vision. Colour vision anomalies in patients with lesions of the retina, optic chiasma and post-occipital centre. In: Colour 69. Gottingen: Musterschmidt, 1970: 88-96.

19 Chisholm IA An evaluation of the Farnsworth-Munsell 100 hue test as a clinical tool in the investigation and management of ocular neurological deficit. Trans Ophthalmol Soc ment of ocular neurolog

20 Griffin JF, Wray SH. Acquired colour vision defects in retrobulbar neuritis. Am f Ophthalmol 1978; 86: 193-201.

21 Fallowfield L, Krauskopf J. Selective loss of chromatic sensitivity in demyelinating disease. Invest Ophthalmol Vis Sci 1984; 25: 771-3.

22 Ferris FL, Kassoff A, Bresnick GH, Bailey I. New visua acuity charts for clinical research. Am $\mathcal{F}$ Ophthalmol 1982, 94: $91-6$.

23 Cox J. Unilateral color deficiency, congenital and acquired. f Opt Soc Am 1961; 51: 992-9.

24 Nikoskelainen E. Symptoms, signs, and early course of optic neuritis. Acta Ophthalmol (Kbh) 1975; 53: 254;71.

25 Wildberger HGH, van Lith GHM. Colour vision and visually evoked response (VECP) in the recovery period of optic evoked response (VECP) in the recovery perid
neuritis. Mod Prob Ophthalmol 1975; 17: 320-4.

26 Pinckers A, Verriest G. Resultats de tests cliniques de la vision des couleurs dans la sclerose en plaques. Bull Soc belge Ophtal 1982; 199-200: 131-44.

27 Tsukamoto M, Adachi-Usami E. Colour vision in multiple sclerosis with optic neuritis. Acta Soc Ophthalmol fap 1987, 91: 613-21.

28 Zeller RW. Ocular findings in the remission phase of multiple sclerosis. Am $\mathcal{f}$ Ophthalmol 1967; 64: 767-72.

29 Fleishman JA, Beck RW, Linares OA, Klein JW. Deficits in visual function after resolution of optic neuritis. Ophthalmology 1987; 94: 1029-35.

30 Engell T, Trojaborg W, Raun NE. Subclinical optic neuropathy in multiple sclerosis. Acta Ophthalmol (Kbh) 1987; 65 $735-40$

31 Linksz A. The clinical characteristics of acquired color-vision defects. In: Straatsma BR, Hall MO, Allen RA, et al, eds. The retina: morphology, function and clinical characteristics. Berkeley: University of California Press, 1969: 58392.

32 Burde RM, Gallin PF. Visual parameters associated with recovered retrobulbar optic neuritis. Am $\mathcal{f}$ Ophthalmol 1975 79: 1034-7.

33 Sanders EACM, Volkers ACW, van der Poel JC, Van Lith GHM. Estimation of visual function aftr optic neuritis: comparison of clinical tests. $\mathrm{Br} \mathcal{F}$ Ophthalmol 1986; 70: 91825.

34 Patterson H, Heron JR. Visual field abnormalities in multiple sclerosis. I Neurol Neurosurg Psychiatry 1980; 43. 205-8.

35 Sanders EACM, Volkers ACW, van der Poel JC, Van Lith GHM. Visual function and pattern visual evoked response in optic neuritis. Brf Ophthalmol 1987; 71: 602-8.

36 Miller DH, Newton MR, van der Poel JC, du Boulay EPGH, Halliday AM, Kendall BE, et al. Magnetic resonance imaging of the optic nerve in optic neuritis. Neurology 1988; 38: 175-9. 